\title{
Cinefilia, cult movies e o filme Bastardos inglórios, de Quentin Tarantino
}

Marina Soler Jorge

Resumo: Este artigo tem como objetivo discutir as aproximações entre a cinefilia e os cult movies com base na análise do filme Bastardos inglórios, de Quentin Tarantino (2009). O amor cinéfilo, conforme surge nos anos 1950 a partir da crítica dos Cahiers du Cinéma, legitima filmes que correm à margem do gosto elevado francês e abraça obras até então consideradas menores. Nesse processo, cria uma teoria e uma "política" que colocam um cinema B no rol das manifestações elevadas. O fenômeno dos cult movies também tenta a seu modo legitimar o "mau gosto", dessa vez por meio de práticas sociais que preferem antes cultuar o maldito a inseri-lo entre os bens culturais elevados. Tarantino opera uma junção das duas formas de amor ao cinema, abraçando ao mesmo tempo a citação àquilo que é marginal e àquilo que é elevado, numa esvaziamento pós-moderno das fronteiras culturais.

Palavras-chave: cinefilia; cult movies; Quentin Tarantino

Abstract: Cinephilia, cult films and Quentin Tarantino's film Inglourious Basterds - This paper discusses the similarities between cinephilia and cult films based on an analysis of Tarantino's 2009 movie Inglourious Basterds. Cinephilia, which emerged in the 1950s from the critique of the French film magazine Cahiers du Cinéma [Notebooks on Cinema], legitimizes films outside the scope of French highbrow taste, and encompasses artworks theretofore considered of lesser importance. In this process, cinephilia creates a theory and a policy that place B grade movies on the list of highly artistic manifestations. In its own way, the cult film phenomenon also seeks to legitimize "poor taste" through social practices that prefer to cultivate "trash" rather than include it on the list of highbrow cultural goods. Tarantino provides a combination of the two forms of love of cinema, embracing at the same time that which is marginal and that which is high culture, in a postmodern shift of cultural boundaries.

Keywords: cinephilia; cult movies; Quentin Tarantino 


\section{Recepção de Bastardos inglórios}

Bastardos inglórios é um filme que nos permite refletir sobre a apropriação erudita da cultura de massas e a apropriação massificada da arte considerada elevada. De forma ainda mais radical que filmes anteriores de Tarantino, esta obra nos coloca os problemas de pensar a cinefilia e os cult movies lado a lado, sem necessariamente abolir a fronteira entre eles, mas tratando-os como merecedores do mesmo nível de nossa atenção.

De modo geral, podemos dividir as críticas de Bastardos inglórios entre os textos que elogiaram aquilo que nele há de prazer cinéfilo e aqueles que, além de considerar o filme um tanto longo, incomodaram-se com a suposta transformação imagética dos judeus em nazistas. Peter Bradshaw, do Guardian, considerou-o "colossal, complacente, um malogro prolixo, um gigantesco anticlímax de duas horas e meia". Jonathan Rosenbaum classificou-o como "extremamente ofensivo bem como profundamente estúpido e [...] moralmente aparentado à negação do Holocausto". Mahola Dargis, do The New York Times, achou-o "desajeitado", "interminável", "repulsivo", "vulgar", e repudiou a comparação entre judeus e nazistas que é sugerida pelo "forno crematório" no qual se transforma a sala de cinema. Nessa mesma linha de argumentação, Daniel Mandelsohn, crítico da Newsweek, comparou o ato de "desenhar" suásticas na testa dos nazistas deixados vivos pelos bastardos com o ato de gravar estrelas de David no corpo dos judeus ${ }^{1}$. Em resposta a críticas desse teor, Michael Rennet argumenta que a comparação é indevida pois falta aos bastardos os métodos de extermínio sistemáticos que eram empreendidos pelos nazistas (RENNET, 2009). Da mesma forma, é possível argumentar que o cinema-crematório não é um dispositivo rotineiro de matar nazistas. Nos termos de Adorno e Horkheimer, faltaria aos Bastardos a herança iluminista que, da razão ilustrada, desembocou em Auschwitz. Ainda sobre este aspecto, Mauro Baptista considerou a reescrita da história empreendida pelo filme como "ambígua", mas considera que ela pode ser lida como uma "resposta de Tarantino [...] à hipocrisia tão cara à chave melodramática do cinema americano" (BAPTISTA, 2010, p. 136).

Outros críticos, como Peter Travers, da Rolling Stone, e Roger Ebert, do Chicago Sun-Times, não pouparam elogios ao filme e pareceram inebriados com a experiência cinematográfica que Quentin Tarantino Ihes ofereceu. Outros ainda, como J. Hoberman, permanecem numa posição mais matizada, apontando o domínio que Tarantino tem do cinema, mas rejeitando o "revisionismo" histórico do filme. Os aspectos positivos do filme tendem a estar associados, nas críticas disponíveis, à atenção dada ao cinema como elemento essencial do enredo. Segundo Ben Walter,

Formalmente e narrativamente, Bastardos inglórios está encharcado de cinema a um grau notável, mesmo para um diretor definido por seu amor aos filmes. [...] se a obra representa uma evolução para o diretor, é porque nele os filmes não são apenas um elemento sutil (ou não tão sutil) em um jogo estético alusivo, pois eles estão, pelo menos, na frente e no centro do filme (WALTERS, 2009, p. 19).

1 Todas as críticas citadas aqui e centenas de outras podem ser acessadas no site do Internet Movie Database: http://www.imdb.com/title/tt0361748/externalreviews. 
Da mesma forma, Stephanie Zacharek, crítica do site Salon.com, considera que "em uma cultura cinematográfica largamente informada por fãs negligentemente entusiasmados, talvez precisemos de Tarantino e de outros cineastas que, como ele, têm algum conhecimento sobre o passado". O espectador contemporâneo, que muitas vezes extasia-se com os produtos pseudointelectuais da indústria cultural, cujo diálogo tanto com os grandes temas da filosofia e das ciências humanas quanto com a história do cinema é bastante superficial, só teria a ganhar diante do enciclopedismo cinematográfico de Quentin Tarantino. Em seu livro sobre cinefilia, Christian Keathley lamenta o aparecimento recente de um novo tipo de cineasta: aquele que faz filmes na ignorância completa do cinema que veio anteriormente (KEATHLEY, 2006, p. 26). Tarantino opta pelo caminho contrário, proclamando-se abertamente devedor da história do cinema que Ihe antecedeu. Para Tarantino, não é possível ser cineasta sem ser cinéfilo. Em seus filmes, a citação é o ato constituinte do fazer artístico.

\section{Cinefilia e Tarantino}

No que se refere à criação de um estilo pessoal, de uma visão de mundo autoral, é possível comparar Tarantino aos realizadores admirados pela cinefilia francesa como Alfred Hitchcock e Howard Hawks. Aquilo que os jovens franceses admiravam nesses dois realizadores - a atenção ao próprio cinema como linguagem específica e não reduzível ao tema ou ao roteiro - pode ser também atribuída a Tarantino. Ainda que os filmes desse diretor sejam desiguais e diferentes entre si, é possível identificar um estilo autoral, influenciado tanto pelo cinema clássico norte-americano na sua capacidade de contar uma boa história quanto pelo cinema moderno de Godard e Leone em seu cuidado com a expressividade dos planos. No entanto, há algo de diferente no estilo de Tarantino que não diz respeito apenas à atenção dada ao cinema como linguagem, mas à atenção dada ao cinema através da profusão de citações à história dessa linguagem. Se Alfred Hitchcock, realizador quintessencial da cinefilia francesa, parecia muitas vezes mais interessado em explorar os estados psicológicos de seus personagens através da construção e da montagem dos planos do que em contar uma história de suspense - e aí sua atenção à linguagem específica do meio - a motivação maior de Tarantino parece ser exibir seu profundo conhecimento de cinema e de cult movies - e aí sua atenção à história específica do meio como linguagem. Hoje, a experiência de recepção do amante de cinema, cinéfilo ou cultista, não se resume ao abandonar-se às sensações causadas pela projeção cinematográfica - mesmo porque a maioria dos filmes é vista em casa. A experiência de recepção do cinéfilo ou cultista na atualidade pode envolver aquilo que não se refere exatamente ao momento de exibição, como a capacidade de compreender as referências que cada filme faz de outros filmes específicos e o conhecimento daquilo que a crítica tem dito a respeito do filme assistido. É nesse sentido que poderíamos falar de uma experiência antes de domínio crítico do que 
de imersão cinematográfica. A filmografia de Quentin Tarantino é pródiga em referências que nos surpreendem pela capacidade do diretor de dominar completamente subgêneros como o exploitation, o kung ku e o western spaghetti.

Seu estilo autoral, do qual é parte fundamental seu exibicionismo cinéfilo, dirige-se tanto ao conhecimento erudito, identificado aqui ao ato da citação, quanto ao prazer descompromissado, o que possibilita que seus filmes sejam lidos simultaneamente no código do conhecedor de cinema e no do middle-brown. Novamente, é possível dizer que cineastas como Hitchcock ou Hawks também podem ser lidos numa dupla chave: através do olhar erudito cinéfilo, que identifica uma sofisticação na linguagem cinematográfica, e através do olhar "ingênuo" do espectador da cultura de massas, que se diverte com a comédia, o drama, o amor e o suspense de uma trama bem contada. Em relação ao cinema clássico de Hawks e Hitchcock e ao cinema moderno de Godard e Leone, o que Tarantino acrescenta, e que podemos classificar como pós-moderno, na falta de um conceito melhor, é a articulação da apreensão erudita com a apreensão massificada através da citação a gêneros e subgêneros considerados absolutamente menores na história do cinema, explicitando assim a forma através da qual a chave de leitura erudita pode ser utilizada para qualquer produto da indústria cultural. Podemos considerar que seu projeto cinematográfico é nesse sentido reflexivo, pois trata de expor os mecanismos de construção dos códigos de leitura eruditos através de sua atribuição a produtos considerados ostensivamente massificados. Bastardos inglórios é um filme interessante a ser analisado nesse sentido, pois estabelece um diálogo intenso entre os cult movies e a cinefilia, de modo a nos sugerir simultaneamente o processo social de valorização do marginal "em si mesmo" e o processo social de atribuição dos códigos da "verdadeira arte" ao marginal.

O primeiro ponto a ser verificado na relação entre Bastardos inglórios e a cinefilia é a atenção dada ao próprio cinema nos filmes de Tarantino e, em especial, nesta obra específica. Como dissemos, trata-se de um cineasta cinéfilo que faz questão de exibir seu amor ao cinema - porém, como já comentado acima, não necessariamente seu amor cinéfilo por filmes bons, mas sobretudo seu amor cinéfilo por filmes considerados ruins. Isso ocorre, em primeiro lugar, através do enredo do filme, no qual personagens e trama giram em torno do cinema e cujo desfecho leva o cinema a desempenhar um papel fundamental na história, apesar de fantasiosa, da humanidade. É de se notar que praticamente todos os personagens importantes têm ou terão alguma relação com cinema - Shosanna é dona do cinema, Bridget von Hammersmark é atriz, Fredrick Zoller é o astro do filme de Joseph Goebbels, Joseph Goebbels é o comandante da indústria cinematográfica alemã, o tenente Archie Hicox é um crítico cinematográfico e os bastardos terão de se disfarçar de diretores e cinegrafistas italianos para terem acesso à avant-première do filme $O$ orgulho da nação. O tenente Aldo Raine finge ser um dublê chamado Enzo Gorlami, numa possível referência a Enzo Castellari, diretor de Quel Maledetto Treno Blindado (1978) que nos Estados Unidos chamou-se The Inglorious Bastards. Eli Roth fingirá ser um cinegrafista 
chamado Antonio Margheriti, numa referência ao diretor de filmes de terror italiano de mesmo nome. De acordo com Kevin Heffernan, o discurso cinéfilo típico dos Cahiers du Cinéma em sua concepção do cineasta como um autor dotado de estilo pessoal será aplicado, a partir dos anos 1980, com a difusão do home viewing e o lançamento de coleções de obras antes obscuras e "malditas", a cineastas como Mario Bava, Jess FranCo, Antonio Margheriti e outros expoentes do cinema de gênero italiano (KEFFERNAN, 2007, p. 159), que serão cultuados em Bastardos inglórios. A dedicação ao cinema na vida de alguns dos personagens citados - Shosanna, Hicox e Von Hammersmark - não os impede nem por um momento de atearem fogo ou explodirem uma sala de exibição destruindo centenas de rolos para encerrar a Segunda Guerra Mundial. Tarantino opta por não lamentar em nenhum momento a destruição de uma bela sala e das centenas de filmes que nela eram guardados, e parte da diversão do filme é o fato de que, ao mesmo tempo que presta uma homenagem ao cinema, estabelece uma indiferença material em relação aos objetos de amor cinéfilos.

Se os aliados preparam uma armadilha para os nazistas queimando uma sala de exibição, estes são diretamente dirigidos a ela pelas suas próprias convicções do cinema como meio privilegiado de propaganda ideológica para as massas. A concepção do cinema como elemento fundamental da estratégia de guerra é o que leva o alto escalão do Terceiro Reich para a morte. O cinema é portanto instrumentalizado pelos dois lados envolvidos no conflito, mas enquanto os nazistas tem uma concepção da arte como arma de propaganda, os bastardos o utilizam simplesmente como arma. No ato de queimar uma sala de exibição, Bastardos inglórios sugere uma rejeição do uso cinema como instrumento político e ideológico e celebra uma arte livre das demandas morais ou pedagógicas nela investidas pelos nazistas, que a transforma em propaganda, ou pela indústria cultural norte-americana, que a faz hipócrita e melodramática. Contra um cinema de esquerda ou de direita, liberal ou nazifascista, valoriza-se o cinema simplesmente, cuja única função, além da arte e da diversão, será a de ser combustível. Nessa desideologização, Bastardos inglórios nos remete tanto à valorização daquelas obras que não têm lugar na história do cinema por serem consideradas diversão para a plebe ignara, como o filme de kung $f u$, quanto à "política dos autores" dos críticos cinéfilos franceses, que celebraram a arte de um cinema que muitas vezes não tinha, e não queria ter, nem um tema grandioso a contar nem uma posição à esquerda a defender. Segundo Antoine de Baecque, no contexto da cinefilia francesa o conceito de mise-en-scène e a "política dos autores" tinham uma conotação explicitamente apolítica, como forma de desqualificar os debates que permeavam a crítica de esquerda a respeito do caráter ideológico dos filmes soviéticos e da indústria cinematográfica norte-americana (BAECQUE, 2010).

O contexto de Bastardos inglórios - a França ocupada - é anterior à cinefilia como a define Baecque, localizada na França do pós-guerra, quando se tratava de "ver os filmes europeus mutilados ou censurados de antes de 1940" e "recuperar o tempo perdido do 
cinema americano" (BAECQUE, 2010, p. 58). No entanto, a "política dos autores", ou aquilo que está no cerne desse "conceito", pode ser entrevista no diálogo entre Shosanna e Fredrick Zoller sobre realizadores alemães. Diante do agradecimento de Zoller por ter exibido Pitz Palu, Shosanna sugere ter sido obrigada pelas forças de ocupação a organizar uma noite alemã em seu cinema e diz não sentir admiração por Leni Riefenstahl, ao que Zoller indaga: "Mas você admira o diretor Pabst... É por isso que você colocou o nome dele no frontão, mesmo que não tenha sido obrigada". Shosanna desce da escada e coloca-se face a face com Zoller para lhe responder com firmeza e superioridade: "Eu sou francesa. Nós admiramos os realizadores neste país. Incluindo os alemães".

A referência à cinefilia também pode ser notada nos aspectos estilísticos do filme, principalmente no que se refere à atenção a mise-en-scène, à montagem de cortes longos e à prodigalidade dos elegantes travellings. Segundo Mauro Baptista, Tarantino rejeita a cobertura, filmando a cena de modo a impossibilitar uma montagem diferente daquela concebida pelo diretor na hora da filmagem (BAPTISTA, 2010, p. 18). Isso nos sugere a importância da criação de um estilo autoral para esse cineasta e da elaboração de cada plano como um segmento repleto de sentidos e sob seu mais absoluto controle.

A sequência de abertura que constitui o primeiro capítulo do filme, subintitulado "once upon a time... in a Nazi-occupied France" (era uma vez... numa França ocupada pelos nazistas), é prodigiosa em termos de autoexibição de um cineasta em sua capacidade cinéfila de construção de planos e sensações através do domínio da linguagem cinematográfica. Essa sequência surgirá após os créditos iniciais, que se desenrolam embalados pela música de Enio Morricone e remete muito claramente ao gênero western spaghetti. O uso da trilha sonora em Tarantino, como notou Mauro Baptista, tem como resultado chamar a atenção para o próprio cineasta, pois acaba por não apenas dar um ritmo específico à cena, mas também comentá-la a partir de um lugar exterior ao filme:

Nos filmes de Tarantino, o espectador percebe, já nas cenas de abertura, que o filme se assume como uma ficção manipulada por uma instância externa [...]. Todos esses aspectos de estilo evidenciam para o espectador a presença de um narrador que manipula imagens e sons de forma lúdica (BAPTISTA, 2010, p. 34).

Segundo Bourdieu e Darbel, "qualquer manifestação cultural, da gastronomia à música dodecafônica, passando pelo faroeste, pode ser objeto de uma apreensão que vai da mais banal sensibilidade até a apreciação erudita" (BOURDIEU e DARBEL, 2007, p. 165). Assim, é possível conferir "erudição" a um produto considerado menor da indústria cinematográfica desde que a este sejam aplicados códigos de leitura que ultrapassem aquele do senso comum e que sejam portanto típicos dos espectadores "iniciados". É interessante mencionar que as teorias de Bourdieu têm sido utilizadas, no caso do cinema, não tanto para entender como os espectadores das camadas socialmente "superiores" e mais educadas apreciam a alta cultura, mas o porquê de esses mesmos espectadores 
apreciarem obras tidas como "menores" na história da arte, como nos sugerem Jancovich (2002) e Sconce (1995). A menção ao western é exemplar da importância das convenções de interpretação do cinema para a criação de obras de arte. Um gênero tido pela crítica francesa pré-baziniana como aglutinador de filmes inequivocamente comerciais é alçado à condição de arte pelos jovens do Cahiers du Cinéma em sua admiração por John Ford e Howard Hawks. André Bazin valoriza o aspecto mítico, a profunda ligação entre história e paisagem desses filmes que lhes confere uma forma universal (fala a diferentes "povos" e nacionalidades) e considera que o gênero chegou à perfeição nos anos 1940.

Porém, Bazin rejeita e lamenta as apropriações não americanas do western que se difundem no pós-guerra e que contaminam o estilo "puro" dos mestres "autênticos": trata-se de filmes menores, de classificação Z, ultracomerciais e de interesse estético limitado (BAZIN, 2002, p. 230-239). Aquilo que a crítica tradicional francesa depreciava no western, Bazin vai criticar no sur-western. Renato Ortiz comenta a reação dos críticos em relação à apropriação "herética" do western pelo spaghetti: "Eles recusam a incursão italiana junto ao mito sacramentado internacionalmente" (ORTIZ, 1994, p. 113). No entanto, o mesmo fenômeno de leitura "erudicizante" que Bazin empreende em relação ao western "autêntico" será efetuado posteriormente em relação aos subprodutos do gênero. Assim, o western spaghetti, que foi considerado um produto B ou Z da indústria cultural, hoje é colocado, ao menos na versão do mestre Leone, entre as obras esteticamente mais relevantes da história do cinema. Desse modo, o mesmo processo de legitimação que os Cahiers empreenderam com a versão "sagrada" do gênero passa a ocorrer com a versão "profana". Tudo se passa como se a qualidade estivesse sempre lá, naquilo que ficou inadvertidamente classificado como B (ou Z), e a crítica apenas operasse um processo de "reconhecimento" a posteriori do que antes era considerado "lixo". No entanto, em termos sociológicos, trata-se menos de um processo de reconhecimento do que de um processo de criação de uma obra de arte.

Depois dos créditos seguidos da trilha sonora que remete muito ostensivamente ao western spaghetti, temos então vinte minutos, antes do capítulo seguinte, nos quais Tarantino constrói um sofisticado duelo verbal e interpretativo (pois ambos estão representando um papel um para o outro) entre os personagens do camponês La Padite e do Coronel Hans Landa através de planos longos e cuidadosamente construídos para que tenhamos a sensação do desenrolar do acontecimento diante de nós em toda sua grandeza e ambiguidade. O cenário no qual o encontro se dá nos sugere uma terra brutal, na qual a irrupção da violência pode ocorrer a qualquer momento, e o espectador é incentivado a tentar descobrir, interpretando gestos e palavras dos personagens, em que momento afinal essa violência vai irromper. Há uma defesa da imagem-acontecimento, ao gosto baziniano, e da montagem como facilitadora de uma abertura para a complexidade do mundo. É interessante mencionar que se parte dos críticos, entre eles Bazin, não aprovou as incursões estrangeiras do western em território italiano, espanhol e mexicano nos anos 
1940 e 1950, conforme comentamos anteriormente, na recepção de Bastardos inglórios não identificamos nenhum artigo que desaprovasse a abertura spaghetti em território francês ocupado. Pelo contrário, há muitas menções elogiosas a essa sequência. Sinais dos tempos pós-modernos, nos quais os mitos geográficos-temporais relacionados aos gêneros foram desterritorializados e sua releituras não são mais interpretadas como o macular de um solo sagrado.

\section{Tarantino e os cult movies}

Elena Gorfinkel, no artigo "Cult Film, or Cinephilia by Any Other Name", rejeita a oposição entre cultistas e cinéfilos, no que se refere à qualidade daquilo a que assistem ou às práticas sociais que os engendram, e defende que o cultismo é uma vertente dentro da cinefilia. Esta o precede e o engloba, mas não há exatamente oposição entre as duas formas de amor ao cinema. O cultista seria, segundo a autora, um tipo particular de cinéfilo, que escolhe segundo uma lógica diferente seus objetos de veneração. Se considerarmos que, a partir das sugestões da análise sociológica do amor pela arte conforme empreendida por Pierre Bourdieu e Alan Darbel (2007), importa menos a obra sobre a qual recai a admiração do que os processos legitimatórios que justificam essa admiração, podemos considerar aqui que se trata não exatamente de diferenciar qualitativamente as obras cultuadas por cinéfilos e cultistas, mas de diferenciar o processo de produção social do culto. O que diferencia o cinéfilo e o cultista não é aquilo a que assistem, mas a forma de legitimação que justifica a devoção a determinadas obras.

$\mathrm{Na}$ atenção ao próprio cinema como procedimento não apenas de citação, mas de construção de linguagem - na atenção à fotografia, à mise-en-scène, aos movimentos da câmera e à montagem pausada -, Tarantino faz filmes para serem vistos na tela grande, num aspecto também cinéfilo de suas obras, que impelem o espectador à visita ao "templo" para que o desfrute da experiência fílmica seja completo. No entanto, esse cineasta que faz filmes para a sala de cinema foi em boa medida formado, ele mesmo, numa cultura de videolocadora (onde trabalhou como atendente), que lhe deu a oportunidade de tomar contato e dominar completamente o que se referia a gêneros cult, como o filme de kung fu, o exploitation e o blaxploitation. Christian Keathley localiza nos anos 1970 e 1980 o surgimento dos especialistas cultivados em áreas muito específicas do cinema relacionadas sobretudo ao filme B, como as que dizem respeito aos gêneros exploitation, film noir, terror, western etc. (KEATHLEY, 2006, p. 24). No caso de Tarantino, esse é o ambiente que permite o surgimento de um cineasta para quem a cinefilia é parte constituinte do fazer fílmico. Se a lógica da raridade cinéfila tem como uma de suas funções manter a distinção relacionada ao complicado acesso a certas obras cinematográficas, a lógica da acessibilidade do home-viewing permite manter viva a cinefilia sobre bases contemporâneas, possibilitando um domínio crítico de obras marginais em relação à grande indústria 
para todo aquele que tem a oportunidade de frequentar uma boa videolocadora ou fazer downloads pelo computador.

Numa conjunção sem precedentes do amor ao cult com o amor cinéfilo, em Bastardos inglórios a menção a filmes marginais convive com a influência de Bazin, da nouvelle vague e do cinema norte-americano de Hitchcock e Hawks, numa chave de leitura que fala simultaneamente ao cultista, ao erudito e também ao não iniciado (que se diverte ainda que não tenha conhecimento suficiente para pescar as referências). No filme em questão esse jogo é acionado também pela trilha sonora, composta de canções retiradas de trilhas sonoras de outros filme. Para que a referenciemos corretamente, é preciso que o espectador seja simultaneamente cinéfilo e cultista e empreenda uma chave de leitura erudita no que se refere ao procedimento de desvendar a citação. No entanto, Tarantino não fez seu filme "pesado" como a cultura erudita, mas "leve" como a cultura de massas, e por isso fala também àqueles que desejam apenas um bom entretenimento, do qual também faz parte a violência. Em entrevista, Tarantino diz não gostar que os críticos tentem achar a correspondência entre cenas suas e aquelas de outros cineastas, mas admite que ele os encoraja a fazer isso quando exibe conhecimento cinematográfico enciclopédico em seus filmes (entrevista a Ryan Gilbey, 2009, p. 18). É possível dizer que ele se exibe duplamente: exibe-se em sua cinefilia, pelo domínio da linguagem do plano sequência e do cinema como arte, e exibe-se em seu cultismo, pelo domínio daquilo que apenas os verdadeiramente aficionados e cultistas dominam. Podemos dizer, junto com Jeffrey Sconce, citando Pauline Kael, que Tarantino fala àqueles cinéfilos que gostam menos de conversar sobre os filmes bons do que sobre aquilo que amam nos filmes considerados ruins (SCONCE, 2007, p. 2). Sua autoexibição é essencialmente pós-moderna, pois implode as fronteiras entre o que é arte e o que é lixo sem abandonar o entretenimento.

Entender o motivo que leva parte dos espectadores a aderir a filmes violentos é uma questão complexa e multifacetada, que não temos de abordar em profundidade aqui. Kay Dickinson, por exemplo, ao analisar o filme Holocausto canibal (Ruggero Deodato, 1980), considera que a fascinação por filmes violentos "reside não na questão de serem eles 'bons' ou 'maus' filmes, mas no fato de que eles são filmes não resolvidos e nebulosos, que confrontam a estrita noção de hermenêutica que é tão fácil de ser cooptada policamente" (DICKINSON, 2007, p. 183). Eric Lichtenfeld, ao analisar o filme de ação, em sua concepção um gênero que nasce da mistura de elementos do western, do film noir e do filme de gângster, e cujo enredo concentra-se menos na solução de crimes do que na contenção dos criminosos, considera que o excesso de violência é efetivamente a única constante desse gênero. "Sob as técnicas estilísticas, os tropos narrativos e as ressonâncias culturais, estamos efetivamente lidando com uma estética de matar pessoas" (LICHTENFELD, kindle edition). Segundo esse autor, isso nos leva ao desafio de ter de lidar com o fato complexo de que existem espectadores que se divertem com o extermínio fílmico de personagens culpados e inocentes e a respectiva exploração de suas imagens, muitas vezes inclusive em câmera lenta, ao serem eliminados. Além disso, para Lichtenfeld, 
não é possível, ao analisar filmes violentos, evitar a discussão, que se seguiu sobretudo em seguida a massacres em escolas norte-americanas, sobre se esse tipo de imagem tem alguma influência no comportamento da sociedade de modo geral. O autor não nega que imagens violentas podem influenciar a violência no mundo real, mas considera que "é igualmente óbvio que apenas uma cultura já obcecada com a violência pode criar um gênero de filme tão violento quanto o filme de ação" (LICHTENFELD, kindle edition). Já Lucio Piedade, em sua dissertação de mestrado, procura matizar tanto a responsabilidade da sociedade "violenta" quanto a do espectador que sente um prazer considerado inadequado diante das imagens de tortura e sofrimento, inserindo o exploitation entre o rol das satisfações mais banais e culturalmente recorrentes: "Assistir a esses filmes pode ser associado a sentar perto da fogueira para ouvir histórias de assombração, folhear solitário as páginas de uma revista de fotos provocantes, discutir em uma rodinha de amigos os detalhes macabros de algum crime ou ler em um jornal popular as notícias sobre a 'loura do banheiro' ou outras criações do imaginário coletivo" (PIEDADE, 2002, p. 9).

Em Bastardos inglórios, a referência ao exploitation não vem sem ironia em relação ao prazer que o espectador sente diante das cenas de crueldade e violência. Nesse sentido, o filme se inscreve numa moderna tradição de filmes que autorreferenciam os gêneros violentos ao mesmo tempo que ironizam a paixão do cinema pelo excesso que, como nos lembra Lichtenfeld, remete ao "cinema de atrações" que marcou os primeiros anos do meio. Filmes como O Clube da Luta (David Fincher, 1999) ou O exterminador do futuro 2 (James Cameron, 1991) são irônicos ao tematizar uma possível gratificação psicológica e social da violência, no caso do primeiro, ou os excessos do herói violento que, ao receber ordens de não mais matar, mira as pernas de seus alvos. Em Bastardos inglórios a principal menção ao exploitation está na presença de Eli Roth, diretor de $O$ albergue (2005) e $O$ albergue I/ (2007), que faz o personagem que leva a cabo nossos desejos inconscientes (ou conscientes?) de dar ao nazistas a lição que eles merecem. Roth interpreta o bastardo apelidado de Urso Judeu, responsável por esmagar o crânio dos soldados alemães com um taco de beisebol enquanto comemora como tivesse rebatido uma bola. Ele explicita o prazer que decorre da imagem da violência quando, por volta dos 23 minutos de filme, enquanto o Tenente Aldo Raine descreve os suplícios que se abaterão sobre os nazistas, sorri um sorriso de deleite com a perspectiva de agredir até a morte seus inimigos. É Eli Roth, como cineasta, que vai dirigir o "filme dentro do filme" O orgulho da nação, uma obra ostensivamente desprovida de roteiro que consiste numa profusão de soldados aliados mortos pelo alemão Frederick Zoller, enquanto os espectadores nazistas, sobretudo Hitler, divertem-se com as imagens do massacre. Durante a projeção, Hitler diz a Goebbels que O orgulho da nação é seu melhor filme, e o ministro solta uma lágrima de emoção pelo reconhecimento de seu Führer. O espectador de Bastardos inglórios diverte-se com a sugestão de que Hitler deve ser um idiota por gostar daquele lixo cinematográfico ou que a indústria cinematográfica de Goebbels é tão ruim que ele não tem parâmetro. No entanto, também é sugerido que o comportamento de Hitler e do público nazista não é diferente do 
comportamento do próprio público dos filmes de Tarantino, que se diverte com o excesso de sangue e violência de suas obras e que também gosta de coisas consideradas ruins. Também é sugerida uma comparação entre Tarantino e Goebbels, pois assim como Hitler considera $O$ orgulho da nação o melhor filme deste, na última cena do filme o tenente Aldo Raine sugere que Bastardos inglórios é a melhor obra daquele. Assim, a sequência da exibição de $O$ orgulho da nação e a sequência final nos remete à autoironia de um cineasta que, ao mesmo tempo que nos oferece um espetáculo estúpido, nos compara e se compara, como espectadores e diretor, aos que gostam desse espetáculo.

Gostamos da violência de Bastardos inglórios, no entanto, não apenas porque, na linha de argumentação de Ismail Xavier sobre o prazer voyeur de Janela indiscreta (XAVIER, 2003, p. 72-80), encontramos nela uma válvula de escape para realizar nossas fantasias agressivas (os desejos ligados à pulsão de morte) que na vida prática não podemos realizar. O que é novo aqui é que Tarantino nos dá um motivo socialmente aceitável para torcermos pela ação do taco de beisebol, pelo escalpelamento e pelo cinema transformado em inferno. Todos sabemos para qual lado devemos torcer em Bastardos inglórios. Apenas acontece de esse lado utilizar de meios cruéis e da violência, e não de bons argumentos e lições de humanidade - afinal, como diz o coronel Aldo Raine, "nazista não tem humanidade".

Parte da crítica sobre o filme chamou a atenção para o aspecto de vingança pessoal envolvido no plano de Shosanna, e encontrou nessa vingança uma referência aos filmes de kung fu que costumam ter como mote um personagem buscando responder com violência ao assassinato de alguém da família mesmo que esse processo leve à sua própria morte (é também o tema de Kill Bill). No entanto, penso que em Bastardos inglórios a vingança ultrapassa a dimensão pessoal e se torna social e histórica, e esse é um dos motivos para o espectador regozijar-se com a execução final do plano. Trata-se de vingar todo um passado, milhões de judeus, de aliados e também de civis alemães mortos durante a Segunda Guerra. Da mesma forma, esculpir suásticas na testa dos nazistas também não é apenas uma questão de sadismo dos bastardos, mas ultrapassa a intenção da tortura e da mutilação. Trata-se de não permitir que os praticantes de crimes contra a humanidade misturem-se aos demais cidadãos do mundo. É preciso encontrar uma forma de marcar essas diferenças para que o nascimento desse horror no seio da civilização nunca mais seja esquecido. As fronteiras entre as nações europeias, entre a alta cultura e a cultura de massas e entre cinefilia e cult movies podem ser apagadas, mas não as fronteiras que separaram os nazistas dos demais. Nesse processo, Tarantino nos deu um motivo para usufruirmos sem culpa não apenas de sua arte cinéfila, mas também da violência que um cinema de excessos pode nos oferecer.

Marina Soler Jorge é professora adjunta do Depto de História da Arte da Escola de Filosofia, Letras e Ciências Humanas Unifesp e doutora em Sociologia pela FFLCH - USP.

marina.soler@unifesp.br 


\section{Referências}

ADORNO, Theodor. A indústria cultural: o esclarecimento como mistificação das massas. Dialética do esclarecimento. Rio de Janeiro: Jorge Zahar, 1985.

BAECQUE, Antoine. Cinefilia. São Paulo: Cosac \& Naify, 2010.

BAPTISTA, Mauro. O cinema de Quentin Tarantino. Campinas: Papirus, 2010.

BAZIN, André. Qu'est-ce que le cinema? Paris: Les Éditions du Cerf, 2002.

BENJAMIN, B. A Nazi's Worst Nightmre. In: Am Cinematographer, 90, n. 9, September 2009, p. 44-55.

BOURDIEU, Pierre. A distinção. São Paulo/Porto Alegre: Edusp/Zouk, 2008. Edusp, 2007.

DARBEL, Alain. O amor pela arte - os museus de arte na Europa e seu público. São Paulo:

DICKINSON, Kay. Troubling Synthesis - The Horrific Sights and Incompatible Sounds of Video Nasties. In: SCONCE, Jeffrey (Ed.). Sleaze Artists - cinema at the margins of taste, style, and politics. Durham and London: Duke University Press, 2007.

GILBEY, Ryan. Days of Glory. In: Sight \& Sound, n. 19, n. 9, setembro 2009, p. 16-21.

GORFINKEL, Elena. Cult Film or Cinephilia by another name. In: Cineaste, winter 2008, p. 33-38.

JANCOVICH, Mark. Cult Fictions: Cult Movies, Subcultural Capital and the Production of Cultural Distinctions. In: Cultural Studies. Routledge, London, 2002, 16 (2): 306-322.

HOBERMAN, J.; ROSENBAUM, Jonathan. Midnight Movies. New York: Da Capo Press, 1983.

KEATHLEY, Christian. Cinephilia and History, or The Wind in the Trees. Bloomington: Indiana University Press, 2006.

HEFFERNAN, Kevin. Art House or House of Exorcism? The changing Distribution and Reception Contexts of Mario Bava's Lisa and the Devil. In: SCONCE, Jeffrey (Ed.). Sleaze Artists - cinema at the margins of taste, style, and politics. Durham and London: Duke University Press, 2007.

LICHTENFELD, Eric. Action Speaks Louder - violence, spectacle and the American action movie. Westport: Praeger, 2004.

ORTIZ, Renato. Mundialização e cultura. São Paulo: Brasiliense, 1994.

PIEDADE, Lucio. A cultura do lixo - horror, sexo e exploração no cinema. 2002, 222 f. (Dissertação de Mestrado em Multimeios). Instituto de Artes, Universidade Estadual de Campinas, 2002.

RENNET, Michael. Journal of Religion and Film, vol. 13, n. 2, outubro 2009.

SCONCE, Jeffrey.'Trashing' the academy: taste, excess, and an emerging politics of cinematic style. In: Screen, 1995, 36(4): 371-393.

(Ed.). Sleaze Artists - cinema at the margins of taste, style, and politics. Durham and London: Duke University Press, 2007.

WALTERS, Ben. Debating Inglorious Basterds. In: Film Quarterly, vol. 63, n. 2, p. 19-22, 2009.

XAVIER, Ismail. O olhar e a cena. São Paulo: Cosac \& Naify, 2003. 